\title{
INFLUENCE OF OIL PALM SPIKELETS FIBRE ON MECHANICAL PROPERTIES OF LIGHTWEIGHT FOAMED CONCRETE
}

\author{
Siti Shahirah Suhaili, Nurshafikah Nadirah Alias, Md Azree Othuman Mydin*, Hanizam Awang \\ School of Housing, Building and Planning, Universiti Sains Malaysia, 11800, Penang, Malaysia
}

Date received: 06/04/2021 Date accepted: 04/09/2021

*Corresponding author's email: azree@usm.my

DOI: $10.33736 /$ jcest.3980.2021

\begin{abstract}
As issues related to sustainable construction in Malaysia gains more importance, research on the utilization of waste by products especially from oil palm in concrete is vigorously implemented. Utilization of different parts of oil palm fibres in lightweight foamed concrete have garnered positive outcomes in terms of conservation of natural resources, lessening of environmental problem and can improve concrete's durability and mechanical properties. Lightweight foamed concrete (LFC) is well-known as a low-density concrete with a wide range of applications. It is good in compression but poor under flexural load, as it produces multiple microcracks and cannot withstand the additional stress induced by applied forces without supplementary reinforcing elements. Hence this study was performed to examine the potential use of oil palm spikelets fibre (OPSF) in LFC in order to improve its engineering properties. LFC specimens were strengthened with OPSF fibre at different percentages of $0.15 \%, 0.30 \%, 0.45 \%$, and $0.60 \%$. LFC density of $1000 \mathrm{~kg} / \mathrm{m} 3$ was prepared with a constant cement-to-sand ratio of 1:1.5, and cement-to-water ratio of 0.45 . The parameters that had been evaluated were flexural strength, compressive strength and splitting tensile strength. The results revealed that the addition of $0.45 \%$ of OPSF fibre gave the best compressive, bending and splitting tensile strengths result. OPSF fibre in LFC aided to evade the promulgation of cracks in the plastic state in the cementitious matrix.
\end{abstract}

Copyright (C) 2021 UNIMAS Publisher. This is an open access article distributed under the Creative Commons Attribution-NonCommercial-ShareAlike 4.0 International License which permits unrestricted use, distribution, and reproduction in any medium, provided the original work is properly cited.

Keywords: lightweight foamed concrete, oil palm waste, spikelets fibre, flexural strength, compressive strength, tensile force

\subsection{INTRODUCTION}

Though lightweight foamed concrete (LFC) has been extensively studied, some limitations such as low flexural strength still restrict its wider applications. The strength of LFC is determined by different cementitious materials, cement dosage, mix proportion, water-cement ratio, foam volume, foaming agent, curing method, additive, and addition of waste by-product [1]. To a certain extent, the density controls the strength of LFC. Therefore, it is always to seek a balance between strength and density, for the purpose to maximize strength while reducing density as much as possible. Sometimes, this can be achieved through optimizing cementitious materials and selecting high-quality foaming agents and ultralight aggregates. The filler types and inclusion of oil palm biomass will influence the water-solid ratios when concrete density is constant, and the reduction of sand particle size will help to improve strength [2]. The pozzolanic effect of fibre biomass waste is to react with the secondary product, $\mathrm{Ca}$ $(\mathrm{OH})_{2}$ (calcium hydroxide, also known as portlandite), of cement hydration to form additional C-S-H gel (secondary C-S-H). During the pozzolanic reaction, the longer silicate chains are formed as the Ca:Si molar ratio of C-S-H drops. This secondary C-S-H reduces the porosity in bulk cement paste and improves the interfacial bond between aggregate particles and fibre, thus increases the strength, density, and ion diffusion resistance of LFC [3]. Lately, LFC has gained major attention among the industrial players and building material manufacturers owing its excellent thermal and mechanical properties such as high flowability, low self-weight, good thermal performance and sound insulation properties [4]. Besides, LFC is an environmentally friendly building material because of its minimal usage of aggregate and high potential to integrate waste material such as natural fibres. LFC is a mixture of cement paste (slurry) and homogeneous foam introduced using a suitable foaming agent, which can be regarded as self-compacting materials [5]. LFC has an air content of more than $25 \%$ by volume, thus, distinguishing itself from highly air entrained materials. Even though increasing consideration has been given to LFC worldwide, its application in the context of Malaysian construction industry is still in its infancy [6]. However, it has been utilized in several housing and void filling project in Malaysia. Hence this research was performed to inspect the potential utilization of OPSF in LFC to improve its mechanical properties. 


\subsection{MATERIALS AND METHODS}

\subsection{Materials}

There were 5 main materials been used to fabricate LFC which were ordinary Portland cement (OPC), fine sand, surfactant, water, and the additive which was oil palm spikelets fibre. The OPC was supplied by YTL Castle Cement Marketing. All the cement used was in good condition and stored in a covered area. The fine sand utilized in this study was natural fine sand which was obtained from the local supplier. This fine sand had a maximum width of $2 \mathrm{~mm}$ and a 600 -micron sieve, and a passage of $60 \%$ to $90 \%$. The suitability of the sand had to follow BS822:1992 [7]. To produce stable foam, a protein-based foaming agent was used, precisely Noraite PA-1. The foam was produced by a portable foaming generator machine, namely the Portafoam TM-1 machine. The watercement ratio used for this research was 0.45 , because this ratio can achieve reasonable workability [6]. Finally, the fibre used was oil palm spikelets fibre (OPSF), which was obtained from local farm in Seberang Jaya, Pulau Pinang after processing. The OPSF was placed under the sun to dry as shown in Figure 1. Next, Figure 2 shows the surface morphology details of OPSF. Table 1 shows the chemical composition and mechanical properties of OPSF used in this investigation.

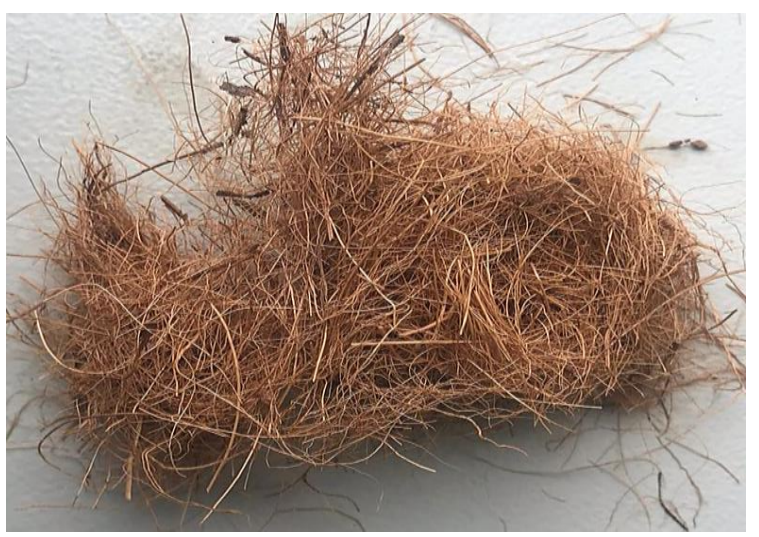

Figure 1 Raw OPSF

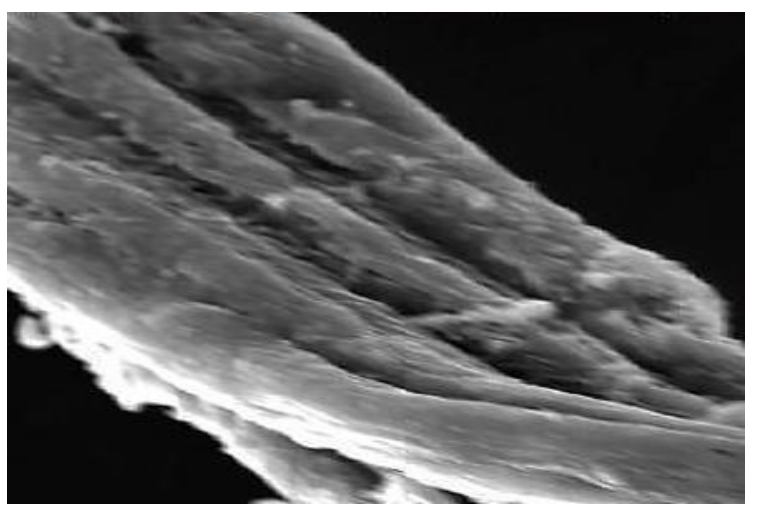

Figure 2 Surface morphology of OPSF

Table 1 Mechanical properties and chemical composition of OPSF

\begin{tabular}{|l|c|}
\hline Composition (units) & Value \\
\hline Cellulose $(\%)$ & 27.7 \\
\hline Hemicellulose $(\%)$ & 31.4 \\
\hline Lignin $(\%)$ & 28.5 \\
\hline Extractives $(\%)$ & 2.3 \\
\hline Density $\left(\mathrm{g} / \mathrm{cm}^{3}\right)$ & 0.94 \\
\hline Length $(\mathrm{mm})$ & 19 \\
\hline Diameter of fibre $(\mu \mathrm{m})$ & 12.45 \\
\hline Diameter of lumen $(\mu \mathrm{m})$ & 6.81 \\
\hline Tensile strength $(\mathrm{MPa})$ & 139 \\
\hline Elongation at break $(\%)$ & 11.41 \\
\hline Young's modulus $(\mathrm{GPa})$ & 12.9 \\
\hline
\end{tabular}




\subsection{Mix Design}

For this investigation, a total of five mixes and a density of $1000 \mathrm{~kg} / \mathrm{m}^{3}$, were prepared accordingly. The percentages of the OPSF used were $0.15 \%, 0.30 \%, 0.45 \%$ and $0.60 \%$. These four percentages were opted because during the pilot study, the authors had found that beyond $0.60 \%$ addition of OPSF, homogenous mix can't be obtained and the foam that was added in the mix quickly broken down. For entire mix, the sand-cement ratio utilized was 1:1.5 and the water-cement ratio used was kept constant at 0.45 . Table 2 demonstrates the mix design of LFC of this study.

Table 2 LFC mix design

\begin{tabular}{|c|c|c|c|c|c|}
\hline Density $\left(\mathrm{kg} / \mathrm{m}^{3}\right)$ & OPSF $(\%)$ & Mix Ratio & Cement $(\mathrm{kg})$ & Sand $(\mathrm{kg})$ & Water $(\mathrm{kg})$ \\
\hline 1000 & - & $1: 1.5: 0.45$ & 37.47 & 56.20 & 16.86 \\
\hline 1000 & 0.15 & $1: 1.5: 0.45$ & 37.47 & 56.20 & 16.86 \\
\hline 1000 & 0.30 & $1: 1.5: 0.45$ & 37.47 & 56.20 & 16.86 \\
\hline 1000 & 0.45 & $1: 1.5: 0.45$ & 37.47 & 56.20 & 16.86 \\
\hline 1000 & 0.60 & $1: 1.5: 0.45$ & 37.47 & 56.20 & 16.86 \\
\hline
\end{tabular}

\subsection{Experimental Setup}

Tests were carried out investigating the mechanical properties with the inclusion of OPSF which includes flexural test, compression test and splitting tensile test.

\subsubsection{Flexural test}

For the flexural test, prism of 100mm x 100mm x 500mm was utilized according to ASTM C293 / C293M [8]. Three-point flexural test was opted to obtain the flexural strength of LFC. Three specimens were prepared, and test and average result of flexural test was taken as final result. Figure 3 shows the setup for the flexural test.

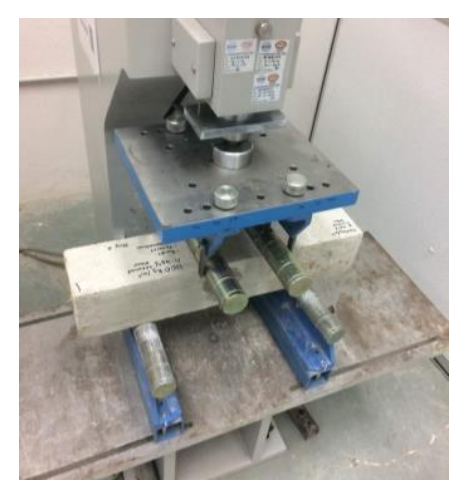

Figure 3 Flexural test of LFC

\subsubsection{Compression test}

The specimen size for compression test is $100 \mathrm{~mm} \times 100 \mathrm{~mm} \times 100 \mathrm{~mm}$ cube which was performed according to BS EN 12390-3 [9] standard. Figure 4 shows the arrangement of the compression test.

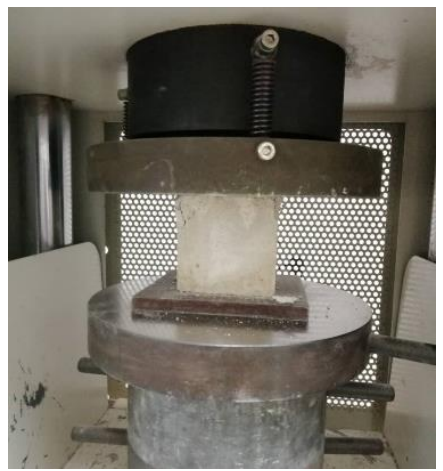




\subsubsection{Splitting tensile test}

As for splitting tensile strength, cylinder of $100 \mathrm{~mm}$ diameter $\mathrm{x}$ 200mm height was considered according to ASTM C496/C 496M [10] standard. Three specimens were prepared and test and the average reading from these three results of flexural test was taken as the final result. Figure 5 shows the setup for the flexural test. The cylindrical specimen was clamped properly to ensure equal distribution of tensile load during the test.

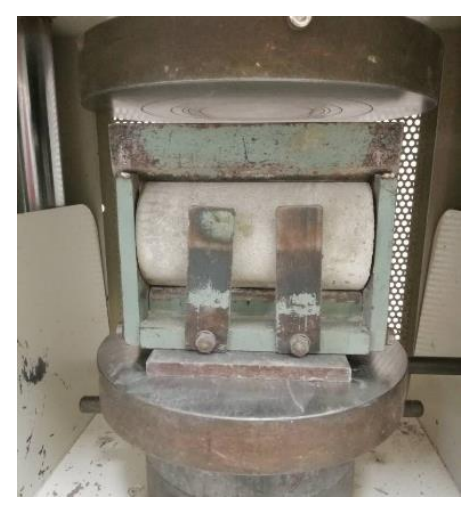

Figure 5 Splitting tensile test arrangement

\subsection{RESULTS AND DISCUSSION}

\subsection{Flexural Strength}

Generally, the flexural strength of LFC with the inclusion of OPSF fibre show trend of increment spite of the percentages of fibre included into LFC. Fig. 6 shows the result of flexural strength attained for the $1000 \mathrm{~kg} / \mathrm{m}^{3} \mathrm{LFC}$ considered in this study. The control mix showed the lowest flexural strength display only a slight increment along with the testing age from day-7 to day-60. Though, LFC specimens with the addition of OPSF fibre show a significant increment in flexural strength by the testing age. At day-28, the flexural strength of control LFC was $2.86 \mathrm{~N} / \mathrm{mm}^{2}$. The optimum percentage of OPSF fibre that gave the best result of flexural strength was $0.45 \%$. The highest flexural strength accomplished at day 60 were $3.99 \mathrm{~N} / \mathrm{mm}^{2}$ with the presence of $0.45 \%$ percentage of OPSF. Nevertheless, undue OPSF percentage included into LFC (more than $0.45 \%$ ) may lead to reducing the bonding between the cement matrix and the fibre [11,12]. Utilization of a $0.45 \%$ volume fraction of OPSF can be considered an optimal percentage for this type of concrete based on the increment of results obtained. High flexural strength attained is due to the reduction of porosity in LFC mixes.

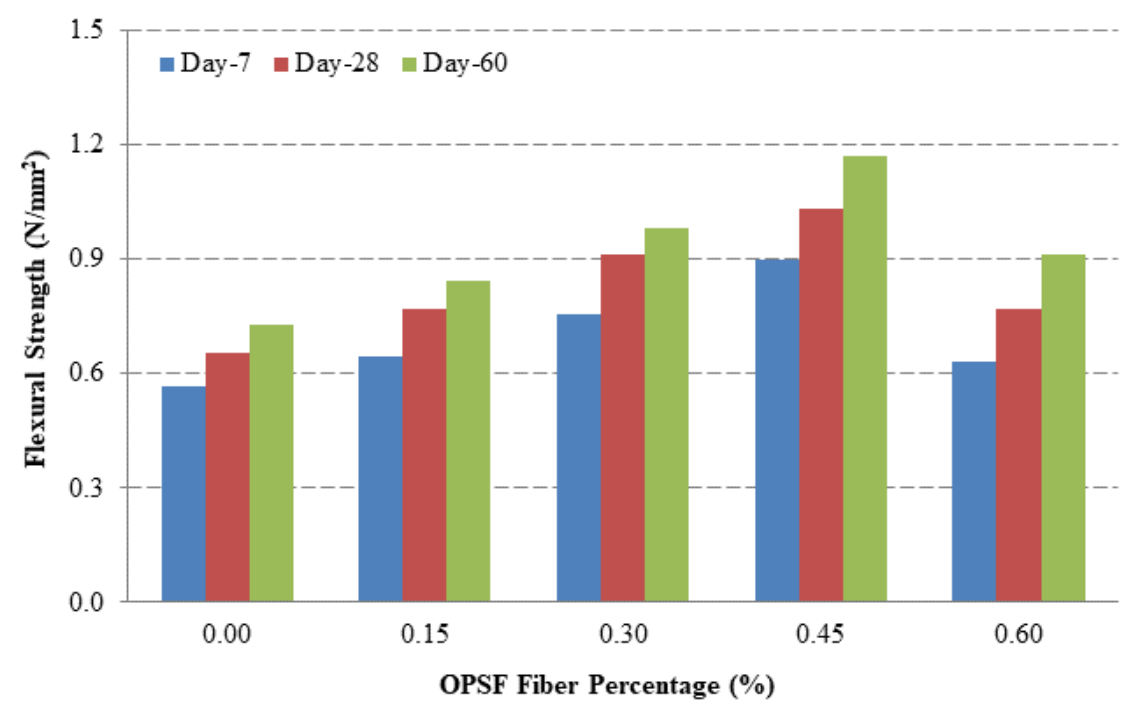

Figure 6 Bending strength of LFC with different percentages of OPSF 


\subsection{Compressive strength}

Fig. 7 shows the results of the compressive strength with different percentages of OPSF. Same as flexural strength, the optimum percentage of OPSF that gave the best compressive strength was $0.45 \%$. The highest compressive strength achieved at day- 28 was $3.59 \mathrm{~N} / \mathrm{mm}^{2}$, with the addition of $0.45 \%$ of OPSF fibre compared to control sample which only achieved compressive strength of $2.86 \mathrm{~N} / \mathrm{mm}^{2}$. Above $0.45 \%$ of OPSF addition, non-uniform scattering of fibres was detected, which resulted in the lessening of the compressive strength. At the optimum level of fibre addition, OPSF and the LFC cementitious matrix reached maximum compaction, which lead to excellent mix consistency [13,14]. As LFC encompasses of large void size in the matrix, micro cracks will take place at the transition zone between the LFC matrix $[15,16]$.

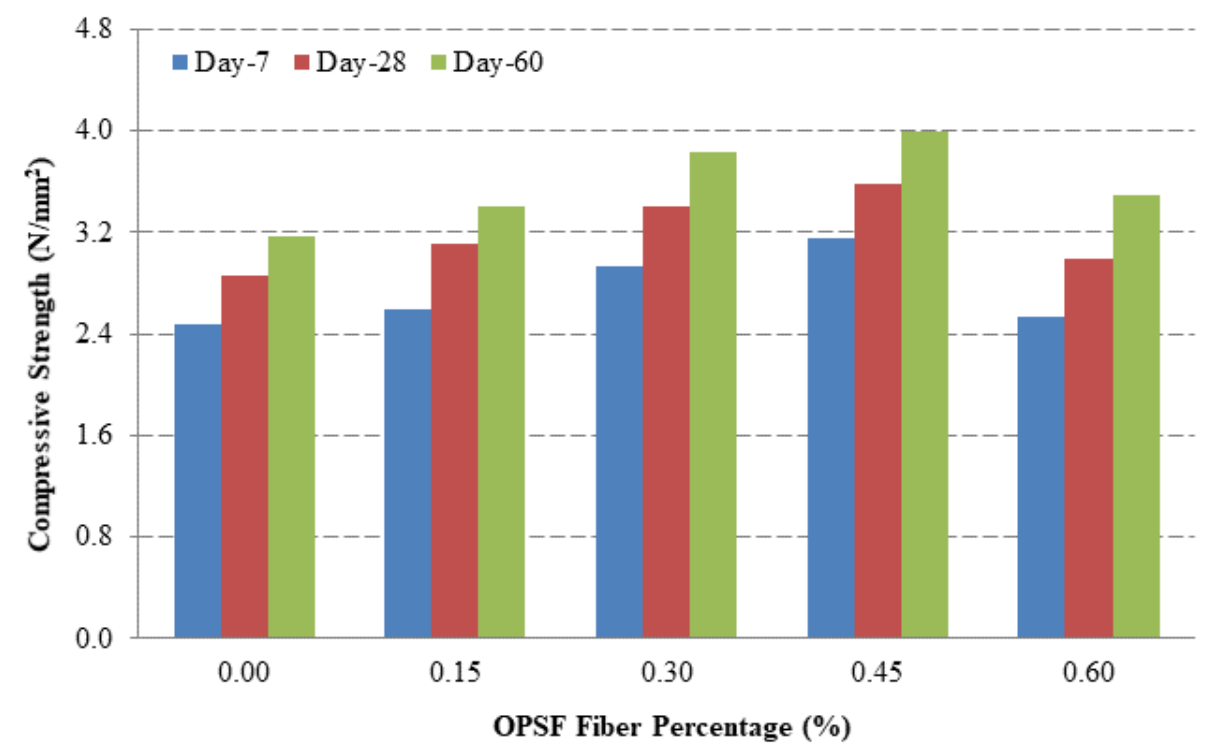

Figure 7 Compressive strength of LFC with different percentages of OPSF

\subsection{Splitting Tensile Strength}

Figure 8 visualized the results of splitting tensile strength of LFC with different percentages of OPSF. The highest splitting tensile strength attained at day- 28 was $0.72 \mathrm{~N} / \mathrm{mm}^{2}$ with the addition of $0.45 \%$ OPSF compared to control specimen (with no fibre inclusion) which only reached compressive strength of $0.41 \mathrm{~N} / \mathrm{mm}^{2}$. Beyond the optimum level of OPSF inclusion, agglomeration of fibres was observed, which results in the drop of tensile strength (at $0.6 \%$ volume fraction of OPSF fibre). The data attained in this study specifies that the addition of OPSF boosts the tensile strength of LFC irrespective on any percentages of OPSF fibre [17, 18]. 


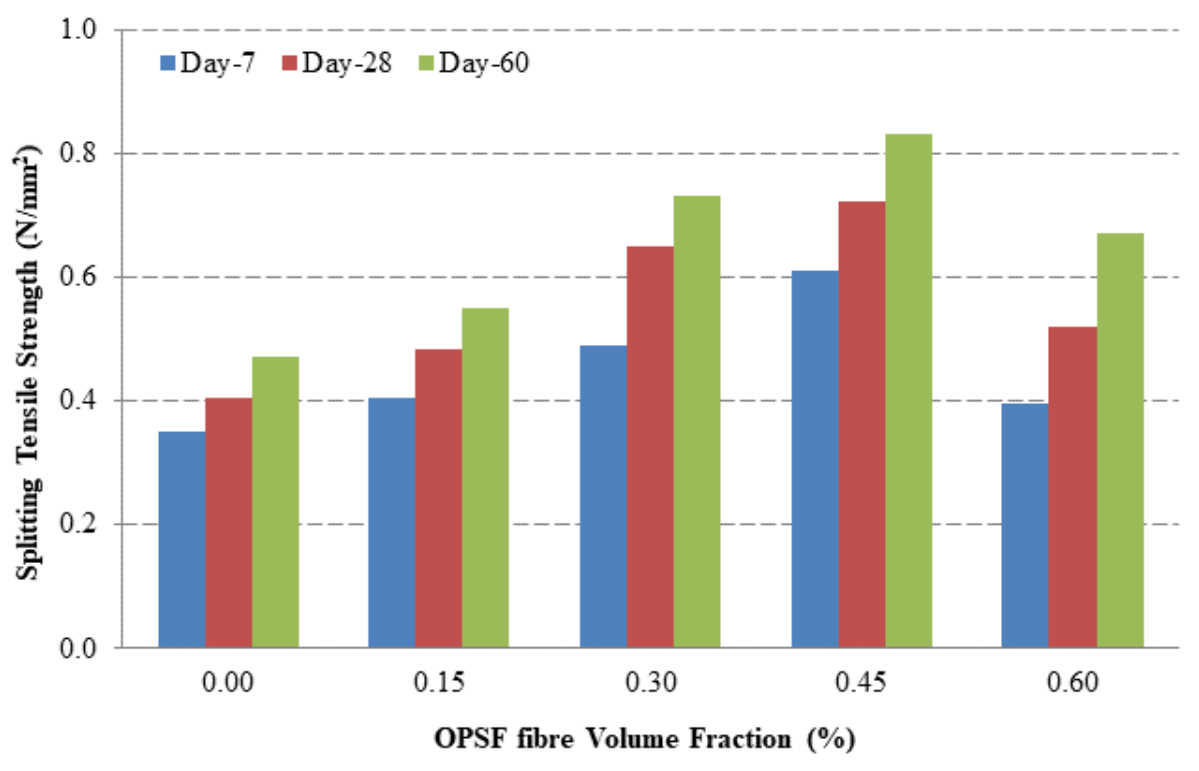

Figure 8 Splitting tensile strength of LFC with different percentages of OPSF

\subsection{Performance Index (PI)}

The axial compressive strength and dry density of LFC has correlated relationship. In theory, higher density of LFC will lead to higher compressive strength $[19,20]$. The density of LFC for this research was control to within $1000 \mathrm{~kg} / \mathrm{m}^{3}$. As the density for each sample was varying, the performance index of LFC was considered to enhance the precision of the results attained from the experimental work. Figure 9 displays the performance index (PI) of the LFC considered in this study. It can be seen that parallel tendency was reached by performance index, in which the performance index is unswervingly proportionate to the specimen's age of curing. The 60-day PI was attained by LFC with $0.45 \%$ inclusion of OPSF, which was $4.20 \mathrm{~N} / \mathrm{mm}^{2}$ per $1000 \mathrm{~kg} / \mathrm{m}^{3}$.

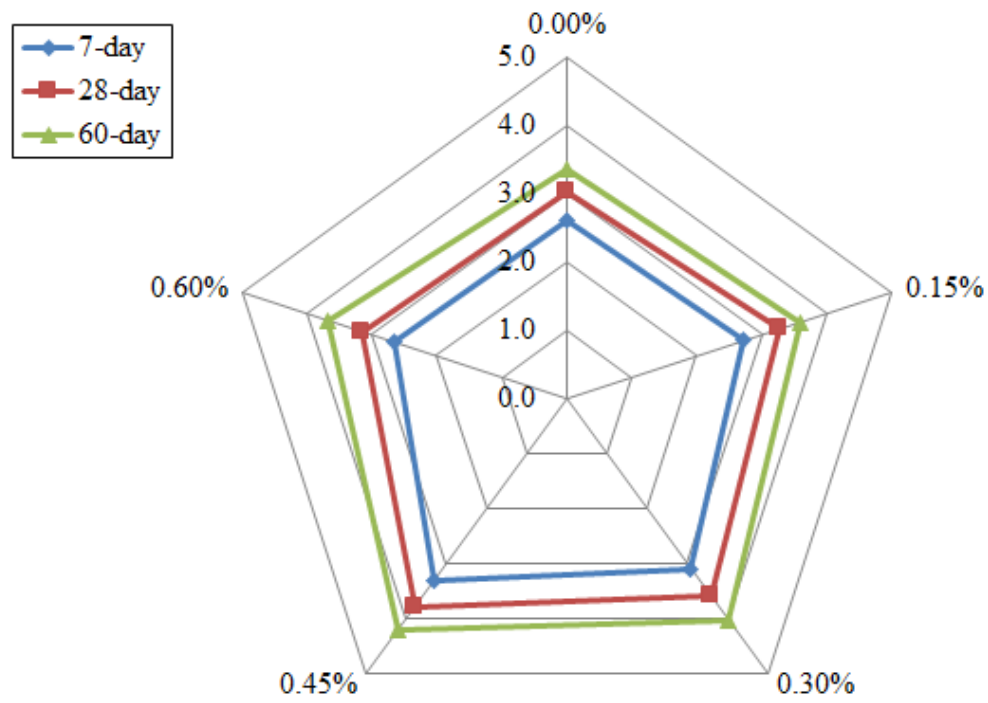

Figure 9 Performance index of LFC of different OPSF percentages

\subsection{CONCLUSION}

From the results obtained from this study, it can be summarized that the strength of LFC improved with the inclusion of OPSF. Though, the different percentages of OPSF included in LFC gave a different result on the mechanical properties of LFC. Overall, $0.45 \%$ of OPSF in LFC gave an outstanding flexural strength, compressive 
strength and splitting tensile strength compared to other percentages considered in this study. OPSF-matrix interface bonding, which is regarded as a coarser surface, is helpful given its surface roughness. Hence, it empowers the OPSF fibre, and matrix mechanical interlocking, thus refining the mechanical properties of LFC.

\section{Conflict of Interests}

The authors declare that there is no conflict of interests regarding the publication of this paper

\section{Acknowledgement}

The authors would like to thank Universiti Sains Malaysia for their funding of this research through the Bridging Grant: Grant No: 304/PPBGN/6316230.

\section{References}

[1] Serri, E., Othuman Mydin, M. A., \& Suleiman. M. Z. (2014). Thermal properties of Oil Palm Shell lightweight concrete with different mix designs. Jurnal Teknologi. 70(1), 155-159. https://doi.org/10.11113/jt.v70.2507

[2] Elrahman, M. A, El Madawy, M. E., Chung, S. Y., Sikora, P., \& Stephan, D. (2019). Preparation and characterization of ultra-lightweight foamed concrete incorporating lightweight aggregates. Applied Sciences, 9(7), 1-12. https://doi.org/10.3390/app9071447

[3] Mahzabin M. S., Hock, L. J., Hossain, M. S., \& Kang, L. S. (2018). The influence of addition of treated kenaf fibre in the production and properties of fibre reinforced foamed composite. Construction and Building Materials, 178, 518-528. https://doi.org/10.1016/j.conbuildmat.2018.05.169

[4] Munir, A., Abdullah, Huzaim, Sofyan, Irfandi, \& Safwan. (2015). Utilization of palm oil fuel ash (POFA) in producing lightweight foamed concrete for non-structural building material. Procedia Engineering, 125, 739-746. https://doi.org/10.1016/j.proeng.2015.11.119

[5] Zhu, W. H., Tobias, B, C., Coutts, R. S. P., \& Langfors, G. (1994). Air-cured banana-fibre-reinforced cement composites. Cement and concrete composites, 16(1), 3-8. https://doi.org/10.1016/0958-9465(94)90024-8.

[6] Sari, K. A. M., \& Sani, A. R. M. (2017). Applications of Foamed Lightweight Concrete. MATEC Web of Conferences, 97, 1-5. https://doi.org/10.1051/matecconf/20179701097

[7] British Standard Institution (1992). BS 882: 1992. Specification for aggregates from natural sources for concrete. London, United Kingdom: British Standards Institute.

[8] ASTM International (2016). ASTM C293 / C293M-16: 2016. Standard Test Method for Flexural Strength of Concrete (Using Simple Beam with Center-Point Loading). West Conshohocken, PA: ASTM International.

[9] British Standard Institution (2011). BS 12390-3: 2011. Testing hardened concrete. Compressive strength of test specimens. London, United Kingdom: British Standards Institute.

[10] ASTM International (2017). ASTM C496 / C496M-17: 2017. Standard Test Method for Splitting Tensile Strength of Cylindrical Concrete Specimens. West Conshohocken, PA: ASTM International.

[11] Hamad, A. J. (2014). Materials, production, properties and application of aerated lightweight concrete. International Journal of Materials Science and Engineering, 2(2), 152-157. https://doi.org/10.12720/ijmse.2.2.152-157

[12] Fu, Y., Wang, X., Wang, L., \& Li Y. (2020). Foam Concrete: A State-of-the-Art and State-of-the-art Practice Review. Advances in Materials Science and Engineering, 6153602, 1-25. https://doi.org/10.1155/2020/6153602

[13] Savastano Jr, H., Warden, P. G., \& Coutts, R.S.P. (2000). Brazilian waste fibres as reinforcement for cement-based composites. Cement and Concrete Composites, 22(5), 379-384. https://doi.org/10.1016/S0958-9465(00)00034-2

[14] Ketty, B., Arsene, M. A., \& Ouensanga, A. (2007). Study of banana and coconut fibers: Botanical composition, thermal degradation and textural observations. Bioresource technology, 98(1), 58-68. https://doi.org/10.1016/j.biortech.2005.11.030

[15] Hanizam, A., \& Ahmad, M. H. (2014). Durability properties of foamed concrete with fiber inclusion. International Journal of Civil, Environmental, Structural, Construction and Architectural Engineering, 8(3), 269-272

[16] Lim, S. K., Tan, C. S., Lim, O. Y., \& Lee, Y. L. (2013). Fresh and hardened properties of lightweight foamed concrete with palm oil fuel ash as filler. Construction and Building Materials, 46, 39-47. https://doi.org/10.1016/j.conbuildmat.2013.04.015

[17] Huang, Z., Zhang, T., \& Wen, Z. (2015). Proportioning and characterization of Portland cement-based ultralightweight foam concretes. Construction and Building Materials, 79, 390-396. https://doi.org/10.1016/j.conbuildmat.2015.01.051

[18] Castillo-Lara, J. F., Flores-Johnson, E. A., Valadez-Gonzalez, A., Herrera-Franco, P. J., \& Carrillo, J. G., GonzalezChi, P.I., \& Li, Q.M. (2020). Mechanical Properties of Natural Fiber Reinforced Foamed Concrete. Materials, 13(14), 3060. https://doi.org/10.3390/ma13143060

[19] Nambiar, E.K.K. Ramamurthy, K. (2008). Fresh state characteristics of foam concrete. Journal of Materials in Civil Engineering, 20, 111-117. https://doi.org/10.1061/(ASCE)0899-1561(2008)20:2(111) 
[20] Klyuev, S. V., Khezhev, T. A., Pukharenko, Y. V., \& Klyuev, A. V. (2018). Fiber Concrete on the Basis of Composite Binder and Technogenic Raw Materials. Materials Science Forum, 931, 603-607. https://doi.org/10.4028/www.scientific.net/MSF.931.603 